\title{
Five years of observations of ozone profiles over Lauder, New Zealand
}

\author{
E. J. Brinksma, ${ }^{1,2}$ J. Ajtic, ${ }^{3}$ J. B. Bergwerff, ${ }^{4}$ G. E. Bodeker, ${ }^{5}$ I. S. Boyd, ${ }^{6,7}$ \\ J. F. de Haan, ${ }^{1,2}$ W. Hogervorst, ${ }^{1}$ J. W. Hovenier, ${ }^{1,8}$ and D. P. J. Swart ${ }^{4}$ \\ Received 13 April 2001; revised 26 October 2001; accepted 29 October 2001; published 30 July 2002.
}

[1] Altitude profiles of ozone $\left(\mathrm{O}_{3}\right)$ over Lauder $\left(45^{\circ} \mathrm{S}, 170^{\circ} \mathrm{E}\right)$ performed using a lidar, ozonesondes, and the satellite-borne Stratospheric Aerosol and Gas Experiment (SAGE II) instrument are presented. These data form one of the few long-term sets of $\mathrm{O}_{3}$ profiles at a Southern Hemisphere location. In the 5 years of data presented, the dominant variation is the annual cycle, the phase and amplitude of which differ below and above $27.5 \mathrm{~km}$. Superposed are irregular episodic variations, caused by various processes. The first process studied is stratosphere-troposphere exchange, characterized by dry and $\mathrm{O}_{3}$-rich air residing in the troposphere, which was found in $21 \%$ of the measurements. The second relates to the positioning of the higher polar vortex over Lauder, often in combination with the exchange of air between midlatitude and subtropical stratospheric regions. We present examples of this which were observed over Lauder during the 1997 winter. This winter was selected for further study because of the record-low $\mathrm{O}_{3}$ amounts measured. The third process is mixing of $\mathrm{O}_{3}$-depleted vortex air with midlatitude air after the vortex breakup. We present one example, which shows that a filament originating from the depleted Antarctic vortex significantly lowers $\mathrm{O}_{3}$ amounts over Lauder around 27 November 1997. There is thus a connection between Antarctic $\mathrm{O}_{3}$ depletion and later decrease of $\mathrm{O}_{3}$ amounts at a Southern Hemisphere midlatitude location, namely Lauder. INDEX TERMS: 0341 Atmospheric Composition and Structure: Middle atmosphere-constituent transport and chemistry (3334); 0340 Atmospheric Composition and Structure: Middle atmosphere - composition and chemistry; 0368 Atmospheric Composition and Structure: Troposphere - constituent transport and chemistry; KEYWORDS: lidar, ozone, sonde, SAGE II, Lauder, intrusion

\section{Introduction}

[2] In this paper, a series of $\mathrm{O}_{3}$ profiles over Lauder, New Zealand $\left(45^{\circ} \mathrm{S}, 170^{\circ} \mathrm{E}\right)$, measured from November 1994 to October 1999, is presented. The data set, obtained with different instruments, is one of the few long-term sets of $\mathrm{O}_{3}$ profiles over a Southern Hemisphere site, opening up the opportunity to investigate several processes determining the

\footnotetext{
${ }^{1}$ Faculty of Sciences, Division of Physics and Astronomy, Vrije Universiteit, Amsterdam, Netherlands.

${ }^{2}$ Now at Climate Research and Seismology Department, Atmospheric Composition Research Division, Royal Netherlands Meteorological Institute (KNMI), De Bilt, Netherlands.

${ }^{3}$ Department of Physics and Astronomy, University of Canterbury, Christchurch, New Zealand.

${ }^{4}$ Air Research Laboratory, National Institute of Public Health and the Environment (RIVM), Bilthoven, Netherlands.

${ }^{5}$ National Institute of Water and Atmospheric Research (NIWA), Lauder, New Zealand.

${ }^{6}$ Environmental Research Institute, National Institute of Water and Atmospheric Research (NIWA), Wellington, New Zealand.

${ }^{7}$ Temporarily at Department of Astronomy, University of Massachusetts, Amherst, Massachusetts, USA.

${ }^{8}$ Also at the Astronomical Institute "Anton Pannekoek," Amsterdam, Netherlands.

Copyright 2002 by the American Geophysical Union. 0148-0227/02/2001JD000737\$09.00
}

$\mathrm{O}_{3}$ budget there. In the work of Brinksma et al. [2000] an intercomparison of these profiles, which number about 200 per year, was presented. There the aim was to validate, correct, and improve the measured $\mathrm{O}_{3}$ profiles. Here we present an extended set of these measurements, pertaining to 5 instead of 3 years. We shift our focus from instruments and algorithms to the various processes that influence the $\mathrm{O}_{3}$ profiles over Lauder. Following this introduction, a brief description of the main processes that determine the midlatitude $\mathrm{O}_{3}$ budget is provided (section 2).

[3] A recent study [Weatherhead et al., 2000] has shown that Southern Hemisphere midlatitudes are among the best locations for detecting possible recovery of the $\mathrm{O}_{3}$ layer. The $\mathrm{O}_{3}$ profile measurements could be used for trend assessment, but since the period covered by lidar data is too short still for accurate trend analysis, we will not derive trends in this paper. Previous trend studies of $\mathrm{O}_{3}$ profiles over Lauder were based on measurements by ozonesondes alone (with a range up to $30-35 \mathrm{~km}$ ). One such analysis, based on measurements between 1986 and 1996, shows decreases of $30 \%$ $\left( \pm 24 \%, 2 \sigma\right.$ accuracy) per decade in upper tropospheric $\mathrm{O}_{3}$ number densities during winter, and decreases of $20 \%$ $( \pm 20 \%, 2 \sigma)$ per decade just after vortex breakup in a small altitude region above the tropopause, but increases of $30 \%$ $( \pm 14 \%, 2 \sigma)$ per decade in the lower stratosphere during late winter, spring, and early summer [Bodeker et al., 1998]. 
[4] $\mathrm{O}_{3}$ loss over Lauder has led to increases in surface ultraviolet radiation levels in the past decades [McKenzie et al., 1999]. Our paper contributes to understanding $\mathrm{O}_{3}$ changes, not by trend analysis, but by examining variations detected in 5 years of data over Lauder. In section 4, annual variations as well as differences between years are discussed. They are interpreted using results of model studies based on longer time series. The three main processes causing interannual variations, which are listed below, are discussed in sections 5 and 6 .

[5] The first process is transport of stratospheric air into the troposphere, which is important for the $\mathrm{O}_{3}$ budget because $\mathrm{O}_{3}$ is quickly destroyed in the troposphere. Transport of midlatitude stratospheric $\mathrm{O}_{3}$, followed by irreversible mixing and subsequent chemical destruction in the troposphere, is the main global sink of $\mathrm{O}_{3}$ [e.g., Holton et al., 1995]. We investigated the frequency with which this type of transport occurred over Lauder, and its seasonal dependence, by studying simultaneous sonde measurements of the mixing ratio profiles of $\mathrm{O}_{3}$ and water vapor (see section 5). Tropospheric air with high $\mathrm{O}_{3}$ and low water vapor content, compared to the surrounding troposphere, was assumed to have originated in the stratosphere, and thus provided evidence of stratosphere-troposphere exchange (STE). The processes involved in this exchange are described in section 2. Potential vorticity (PV) analysis was used to corroborate the stratospheric origin of such air.

[6] The second process investigated involved the positioning of the higher polar vortex over Lauder, often in combination with exchange between the subtropics and midlatitudes (see subsection 6.2). This process caused the episodes of record-low $\mathrm{O}_{3}$ densities over New Zealand in the 1997 winter [Brinksma et al., 1998]. The interaction between the subtropical high troposphere and the midlatitude stratosphere is an important factor for the global budget of stratospheric $\mathrm{O}_{3}$ (and stratospheric water vapor) [Holton et al., 1995]. The interaction between the vortex (edge) and midlatitudes is important because exchange of air could increase the amount of air that can be photochemically processed, and thus could increase the amount of $\mathrm{O}_{3}$ destruction.

[7] The third process investigated occurs between the lower stratospheric polar region and midlatitudes at a time when the vortex has broken up and the polar stratosphere is no longer isolated. In subsection 6.3 we will show evidence that $\mathrm{O}_{3}$-depleted polar stratospheric air was mixed into the midlatitude stratosphere, significantly decreasing $\mathrm{O}_{3}$ column densities over Lauder in late November 1997. This evidence is based on PV values constructed from trajectory analyses, together with $\mathrm{O}_{3}$ profile and Dobson spectrophotometer $\mathrm{O}_{3}$ column density measurements.

\section{Midlatitude Ozone Sources and Sinks}

[8] In this section an overview of sources and sinks that determine the midlatitude $\mathrm{O}_{3}$ budget is presented, providing a rationale for the investigations discussed in the following sections.

[9] Variations of the $\mathrm{O}_{3}$ profiles are caused by global scale transport processes, to which a long-term trend and irregular episodic varations are added. $\mathrm{O}_{3}$ column densities over Lauder are highest in September or October, due to the stronger general circulation which advects $\mathrm{O}_{3}$-rich air from the tropics to midlatitudes, and the obstruction of transport of $\mathrm{O}_{3}$-rich air onto the poles by the vortex. High in the atmosphere (at about $30 \mathrm{~km}$ and higher [Perliski et al., 1989; Bodeker et al., 1998]), local photochemistry is the dominant production process.

[10] The main global sink of $\mathrm{O}_{3}$ is rapid chemical destruction in the troposphere, after stratospheric air has been transported into the troposphere through various irreversible processes [Holton et al., 1995]. The dominant process causing this STE at midlatitudes involves strong deformations of the tropopause, "tropopause folds" [Shapiro, 1980; WMO, 1985; Price and Vaughan, 1993], associated with frontal zones related to the westerly jet stream. In such a tropopause fold the dynamical tropopause (defined as a surface with a constant value of the PV rather than the more usual definition in terms of the temperature gradient) intrudes deeply into the troposphere along a sloping frontal zone, creating a tongue of stratospheric air extending into the troposphere. Tropopause folds have a typical scale of hundreds of kilometers in the lateral direction, and a few kilometers in the vertical direction. High $\mathrm{O}_{3}$ mixing ratios and absolute PV values inside the fold are gradually modified by irreversible small-scale mixing with the surrounding tropospheric air. The return flow from troposphere to stratosphere mainly occurs in the tropics, through cumulus convection [Andrews et al., 1987; Holton et al., 1995]. Also, some two-way transport occurring between the tropical high troposphere and the "lowermost stratosphere" (for definition and discussion, see Holton et al. [1995]) influences the stratospheric ozone budget. In an extensive review of model studies of STE outside the tropics [WMO, 1985] it was indicated that most STE occurs during spring and that during winter STE events are relatively rare.

[11] During winter a strong jet stream around the Antarctic, the "polar vortex," is formed. This polar vortex significantly influences $\mathrm{O}_{3}$ amounts over Lauder in two ways: First, because it influences the dynamical transport; during winter, poleward transport in the lower stratosphere is blocked by the strong winds associated with the vortex edge [Schoeberl and Hartmann, 1991]. In the higher stratosphere, transport does still take place, and diabatic descent of $\mathrm{O}_{3}$-rich air (air with a high $\mathrm{O}_{3}$ mixing ratio) takes place over the vortex. Owing to this descent, the highest $\mathrm{O}_{3}$ column densities in the world are expected at high latitudes in the winter hemisphere. However, this is counteracted by the second vortex-related process: photochemical reactions on the surface of polar stratospheric cloud particles within the springtime vortex, which induce substantial $\mathrm{O}_{3}$ loss in the polar lower stratosphere, leading to what is generally referred to as the "ozone hole" [see Solomon, 1999, and references therein]. Transport of $\mathrm{O}_{3}$ depleted air from the Antarctic after the breakup of the vortex in spring as well as export of $\mathrm{O}_{3}$-depleted air from the vortex edge before its breakup influence $\mathrm{O}_{3}$ profiles over Lauder.

[12] A transport barrier analogous to the vortex has been identified at the edge of the tropics [Trepte and Hitchman, 1992; Fahey et al., 1996]. This subtropical barrier, which 
like the vortex is only present in the winter hemisphere, hampers the two-way exchange of tropical upper tropospheric air and midlatitude lower stratospheric air along isentropes. Filaments of $\mathrm{O}_{3}$-poor air from the high troposphere or lower stratosphere of the subtropics are sometimes observed over midlatitudes [e.g., Waugh, 1993; Brinksma et al., 1998].

\section{Instrument Descriptions and Accuracies}

[13] The $\mathrm{O}_{3}$ profiles presented in this paper were measured with a stratospheric lidar, ozonesondes and the satellite-borne Stratospheric Aerosol and Gas Experiment (SAGE II). SAGE II profiles (version 5.96) within $2.5^{\circ}$ latitude $(\sim 280 \mathrm{~km})$ and $12^{\circ}$ longitude $(\sim 940 \mathrm{~km})$ from Lauder were included. While profiles from ozonesondes typically do not provide reliable data above $30 \mathrm{~km}$, the data set presented here includes the altitude range from 30 to 50 $\mathrm{km}$ where $\mathrm{O}_{3}$ trends are dominated by gas phase chemistry [e.g., Perliski et al., 1989]. Measurements performed with the Lauder-based microwave instrument are under revision and have therefore not been included.

[14] Water vapor mixing ratio profiles over Lauder were derived from balloon sonde measurements of profiles of $\mathrm{O}_{3}$ number density, relative humidity, and air temperature. It was assumed that the specific volume of liquid water is small compared to that of water vapor, and that the ideal gas law is valid for water vapor [Fleagle and Businger, 1980].

[15] The $\mathrm{O}_{3}$ profile modifications suggested by Brinksma et al. [2000] have been implemented. They comprise the use of modified atmospheric parameters and a $50 \mathrm{~m}$ (upward) altitude shift in the lidar data, a downward shift of the sonde data profiles by $125 \mathrm{~m}$ to correct for the ozonesonde response time, and a decrease of the SAGE $\mathrm{II} \mathrm{O}_{3}$ number densities by $2.5 \%$.

[16] The accuracy of the lidar $\mathrm{O}_{3}$ profiles is about $2.5 \%$ (since the precision below $35 \mathrm{~km}$ is better than $1 \%$ and the systematic error is smaller than $2 \%$ [Brinksma et al., 2000]). From these profiles, potential temperature profiles of $\mathrm{O}_{3}$ mixing ratio (hereinafter, $\mathrm{O}_{3}$ mixing ratio profiles) are generated using sonde measurements of the air number density and temperature. The accuracy of the sonde temperature measurements is $0.2 \%$ (since a shielded temperature sensor is used, see Bodeker et al. [1998]). This error is negligible. However, the nonsimultaneity in the sonde and lidar measurements introduces a further inaccuracy in the $\mathrm{O}_{3}$ mixing ratio profiles, which we estimate at about $3 \%$ (based on a comparison of monthly averaged and instantaneous sonde density profiles, done in the framework of the comparison presented by Brinksma et al. [2000]). The total accuracy of the mixing ratio profiles is therefore $5 \%$.

[17] The accuracy of the ozonesonde $\mathrm{O}_{3}$ profiles is about $5 \%$ for altitudes below $32 \mathrm{~km}$ [Bodeker et al., 1998]. These profiles are converted into $\mathrm{O}_{3}$ mixing ratio profiles using temperatures and air number densities measured by the ozonesonde itself, which have a high precision (see above). Therefore the mixing ratio profile accuracy is also estimated at $5 \%$.

[18] The accuracy of the water vapor profiles measured with sondes is a few percent in the troposphere. In the stratosphere these profiles are not reliable. In this paper, we only need to use the tropospheric data, and a 5\% accuracy is good enough for our purposes.

\section{Ozone Profile Time Series}

[19] An overview of $\mathrm{O}_{3}$ profiles measured over Lauder between late 1994 and late 1999 is shown in Figure 1. SAGE II profiles were included when they were measured within $2.5^{\circ}$ latitude $(\sim 280 \mathrm{~km})$ and $12^{\circ}$ longitude $(\sim 940$ $\mathrm{km})$ from Lauder.

[20] An annual cycle in the variation of the $\mathrm{O}_{3}$ number densities is evident, especially between 15 and $25 \mathrm{~km}$, where $\mathrm{O}_{3}$ densities range from about $4 \times 10^{12} \mathrm{~cm}^{-3}$ in spring to $6 \times 10^{12} \mathrm{~cm}^{-3}$ in winter. $\mathrm{O}_{3}$ number densities also exhibit clear interannual variation. By applying a statistical regression model to 10 years of ozonesonde data, Bodeker et al. [1998] showed that $\mathrm{O}_{3}$ variations over Lauder are driven by a combination of dynamical effects, the solar cycle, long-term trends, and some minor other influences. Using a similar analysis, G. E. Bodeker (private communication, 1999) showed that recent winter $\mathrm{O}_{3}$ column densities over Lauder were relatively high in even years and low in odd years. This is related to the quasi-biennial oscillation, which affects the transport of $\mathrm{O}_{3}$-rich air from the tropics to midlatitudes.

[21] In Figure 2 the same data as in Figure 1 are presented, but now as series of the $\mathrm{O}_{3}$ number densities at various constant altitudes. In the left panel the annual variation is evident, while in the right panel, where measurement results are arranged by decimal fraction of the year (and different years are denoted by different colors and plot symbols), extreme values as well as the phase difference observed between annual variations at different altitudes can be more readily distinguished.

[22] Referring to the left panel of Figure 2, at 20 and 22.5 $\mathrm{km}$, differences between odd and even years are apparent. In the even years (1996 and 1998), $\mathrm{O}_{3}$ density values vary smoothly, following approximately an annual variation. In odd years (1995, 1997, and possibly also 1999) a different pattern is observed, since many deviations to lower values are seen. Thus the average $\mathrm{O}_{3}$ column densities in the winters of 1995 and 1997 were lower than those in the even years presented, corroborating the findings of G. E. Bodeker (private communication, 1999). It is also evident from the right panel of Figure 2 that at altitudes below 40 $\mathrm{km}$ most of the low $\mathrm{O}_{3}$ number densities were measured in odd years, especially 1997 . Values higher than average were often measured in even years.

[23] Referring to the right panel of Figure 2, evidently a phase difference exists between annual variations at different altitudes. At $25 \mathrm{~km}$ and lower the minima in the number density occur earlier in the year (in summer) than they do at $30 \mathrm{~km}$ and higher, where minimum values are observed halfway through the year. At the intermediate level, 27.5 $\mathrm{km}$, no clear annual variations are present. This phase difference is due to the different processes responsible for $\mathrm{O}_{3}$ number density changes at various altitudes: to a large extent, the general circulation determines the natural variations in $\mathrm{O}_{3}$ number densities in the lower and middle stratosphere, but influence of the vortex on the lower stratosphere is important during late spring (through the 


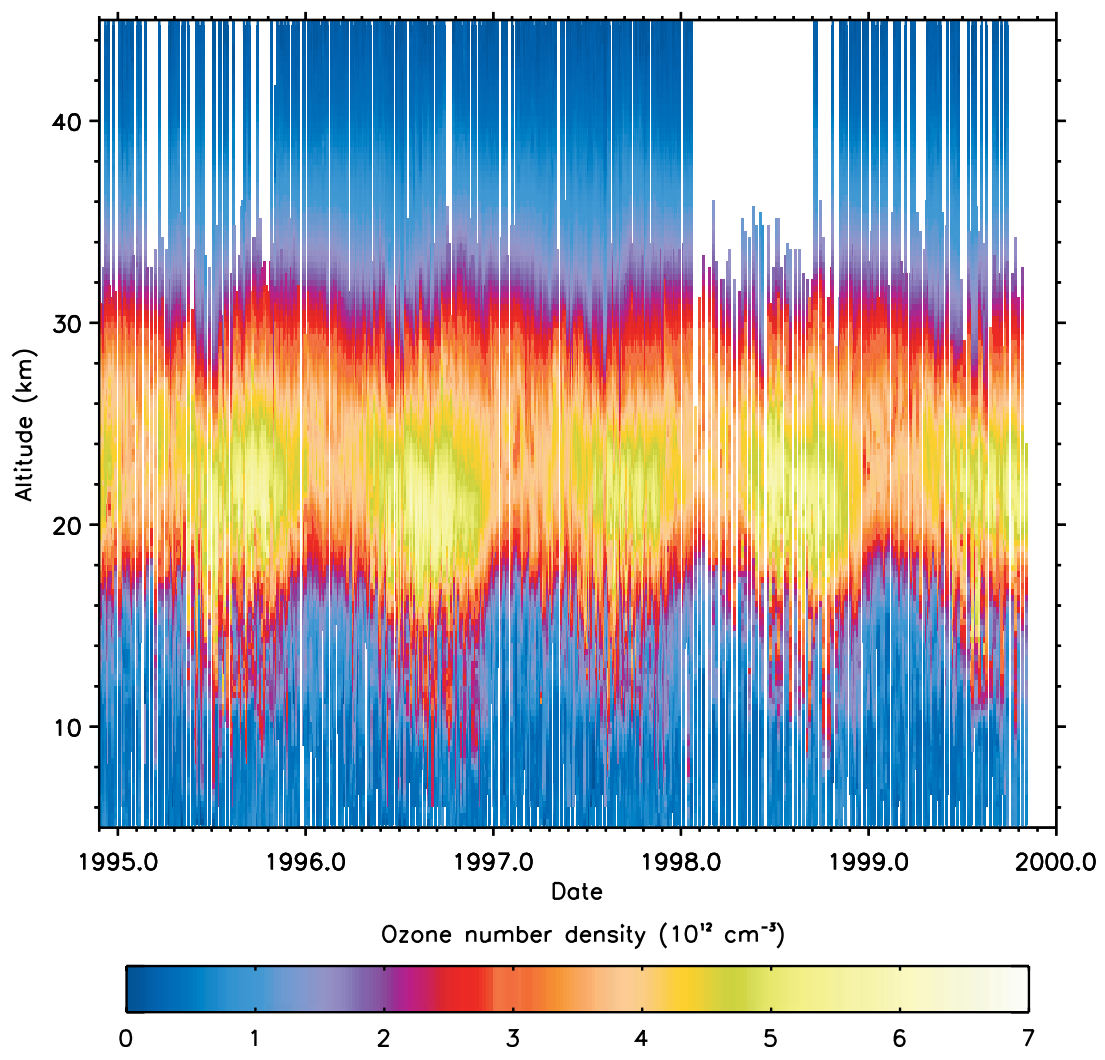

Figure 1. Overview of measured $\mathrm{O}_{3}$ profiles over Lauder between late 1994 and late 1999. Geometric altitude is shown on the vertical axis, and decimal dates are shown on the horizontal axis. $\mathrm{O}_{3}$ number density is indicated by the color scale in the legend bar. Each profile is depicted by one vertical colored line, with voids representing dates without measurements. All lidar and ozonesonde results between 1 December 1994 and 3 November 1999, and all SAGE II results over Lauder between 1 December 1994 and 1 February 1998, are included. From February to August 1998, no lidar measurements were performed.

"dilution effect"), while various irregular exchange processes are also present. Also, tropopause height fluctuations significantly influence $\mathrm{O}_{3}$ in the lower stratosphere. Above about $29 \mathrm{~km}$ an annual cycle in $\mathrm{O}_{3}$ densities is expected over Lauder [Bodeker et al., 1998], due to local $\mathrm{O}_{3}$ production by photochemistry. During midwinter (decimal year fraction 0.48 ), when the amount of solar radiation is lowest (due to the large solar zenith angles), minimum $\mathrm{O}_{3}$ densities are observed at $30 \mathrm{~km}$ and higher (Figure 2, left panel). Since not only the solar irradation, but also local temperature and other factors determine the photochemical reaction rate [Perliski et al., 1989], the maxima observed at these altitudes do not occur exactly at midsummer (decimal year fraction 0.98). A more accurate determination of factors important in the annual variation of $\mathrm{O}_{3}$ above $30 \mathrm{~km}$ will be possible in the future, when a sufficiently long record of lidar and SAGE II measurements will be available.

\section{Intrusions of Stratospheric Air Into the Troposphere}

[24] In this section the occurrence of stratosphere-troposphere exchange (STE) over Lauder is analyzed. Since stratospheric air is $\mathrm{O}_{3}$-rich and dry compared to tropo- spheric air, occurrences of simultaneous local maxima in $\mathrm{O}_{3}$ and local minima in water vapor mixing ratio suggest intrusions of stratospheric air into the troposphere. In subsection 5.1 a single episode of STE over Lauder is discussed in detail, and a PV analysis is applied to verify the stratospheric origin of the layer detected. In subsection 5.2 the frequency with which STE events were observed over Lauder is reported, along with its seasonal dependence.

\subsection{Case Study of STE Over Lauder}

[25] An example of an intrusion of stratospheric air into the troposphere is shown in Figure 3. Water vapor and $\mathrm{O}_{3}$ mixing ratios indicate that relatively dry, $\mathrm{O}_{3}$-rich air was present between 5 and $6 \mathrm{~km}$. On the basis of the change of the slope of the potential temperature gradient (dotted) the tropopause height was estimated to be $8.5 \mathrm{~km}$. The intrusion shown is located at about $3 \mathrm{~km}$ below the tropopause.

[26] High absolute values of PV in the troposphere indicate a stratospheric origin of the associated air. A local maximum of the PV is evident on a map of the vertical cross section of the PV for the longitude of Lauder on 16 April (Figure 4), generated from interpolated National Centers for Environmental Prediction (NCEP) temperature and wind fields [McPherson et al., 1979]. This maximum coincides with the dry, $\mathrm{O}_{3}$-rich layer of air shown in Figure 3, and thus 


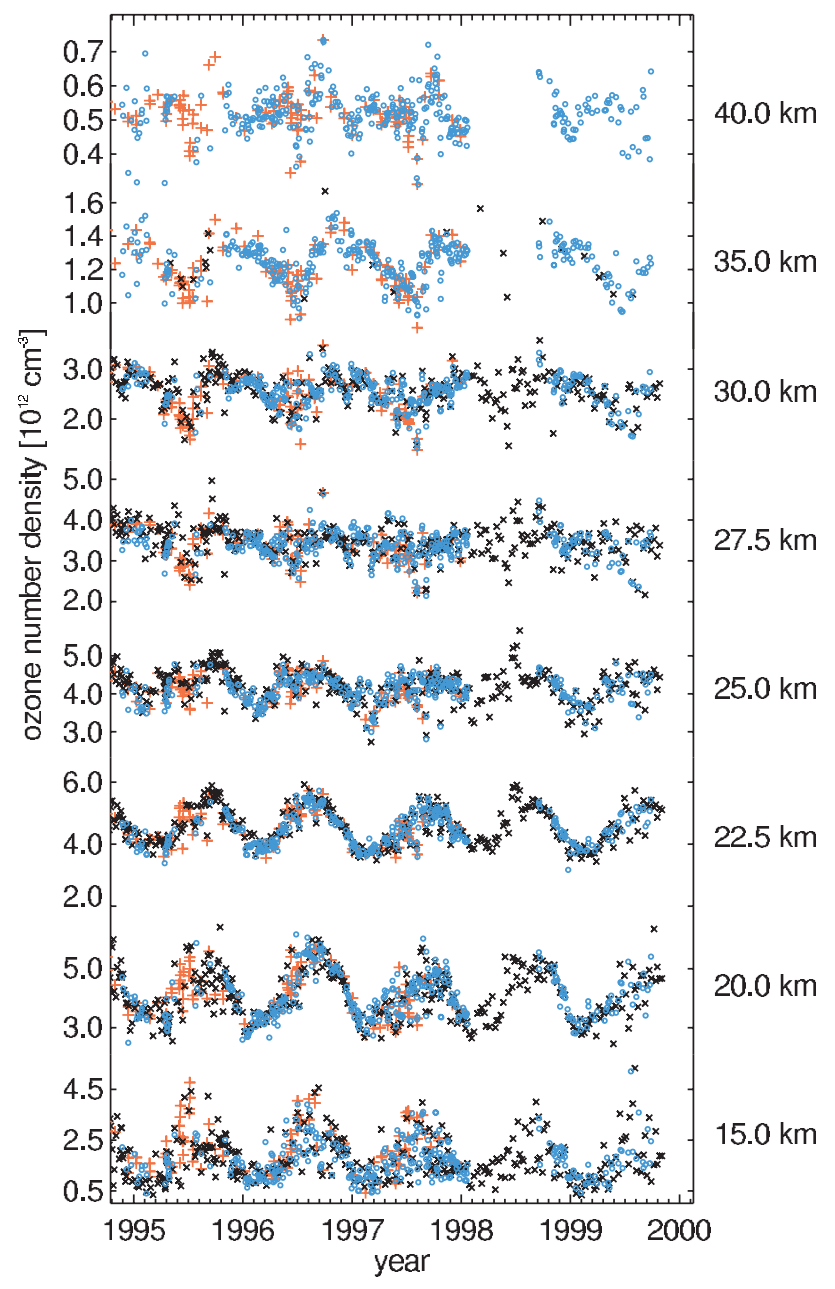

+ sage II $\times$ sondes $\circ$ lidar

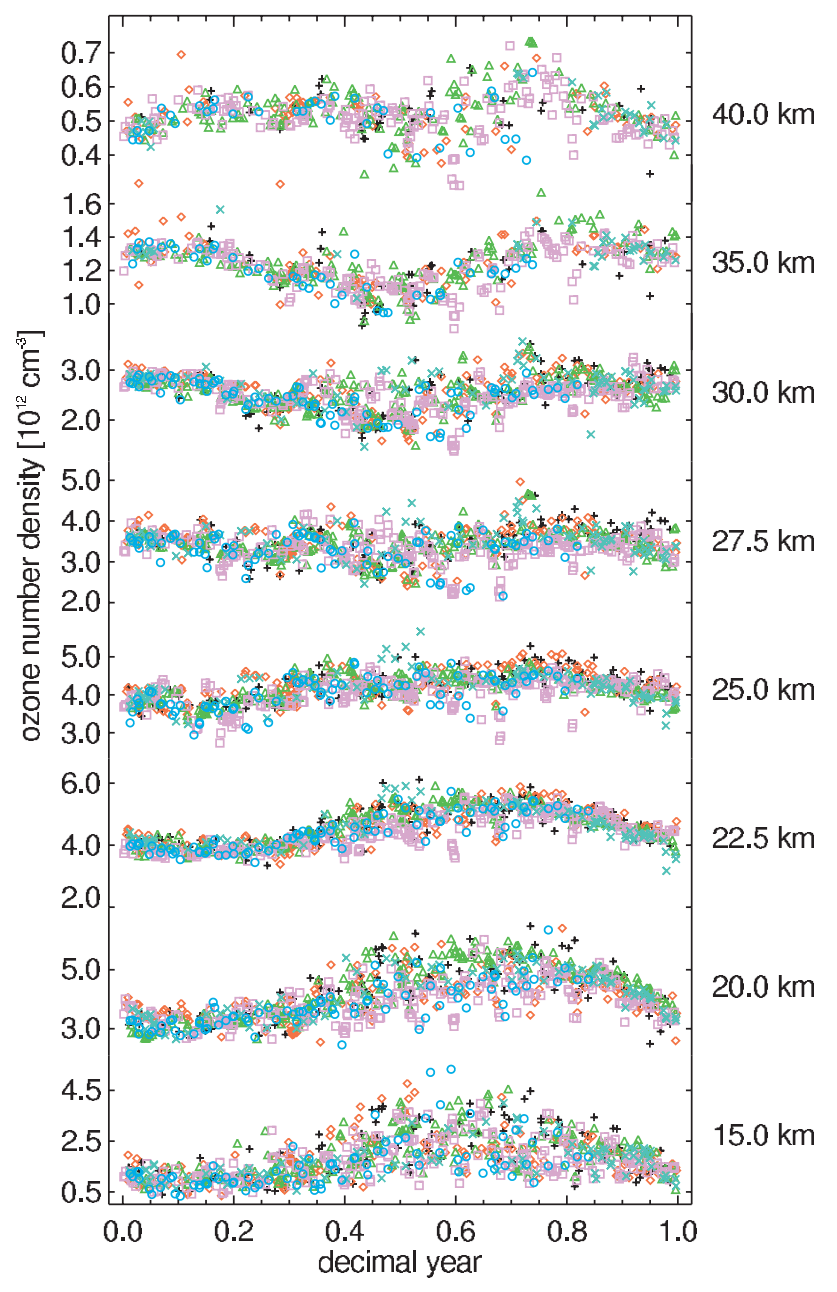

$+1994 \diamond 1995 \quad \Delta 1996 \quad \square 1997 \times 1998 \quad \circ 1999$

Figure 2. $\mathrm{O}_{3}$ number densities measured over Lauder (November 1994 through October 1999) by lidar, ozonesonde, and SAGE II instruments, as a function of time. All available measurements were used, interpolated to the altitudes shown in the labels on the right. (left) Dates on the horizontal axis indicate 1 January of a year. Different plot symbols depict results of different instruments. (right) Numbers on the horizontal axis indicate decimal fraction of the year. Different plot symbols depict different years.

corroborates the stratospheric origin of this layer. Thus the presence of this layer indicates that STE has taken place, although the exact process that caused this exchange remains unknown.

\subsection{Frequency of STE Over Lauder}

[27] We inspected the sonde profiles for the presence of tropospheric peaks in the $\mathrm{O}_{3}$ profile correlated with dips in the water vapor mixing ratio profile. An example was discussed in subsection 5.1. These indications of the presence of formerly stratospheric air were found in $66(21 \%)$ of the 317 sonde results inspected. They were most often located between 4 and $9 \mathrm{~km}$, in $1-1.5 \mathrm{~km}$ thick layers.

[28] To investigate when exchange happened most frequently, statistics are presented for four seasons: summer (December, January, February), autumn (March, April, May), winter (June, July, August) and spring (September, October, November). The number of profiles in which indications of STE is present is shown in Table 1 under the heading N1 and also in the percentage column. Since single exchange events were sometimes detected in two or three consecutive sonde profiles, especially in September through December (when the sonde launch frequency is doubled to twice a week), a distinction between the number of sonde profiles with indications of STE (N1) and the number of STE events (which can be smaller than N1, since consecutive sonde profiles that contain indications of the same STE event are counted as one) should be made. The latter number is listed separately, under the heading N2.

[29] In light of the typical timescale of STE, which is on the order of several days to a week [WMO, 1985], the number of STE events (N2) measured per season or per year should be considered a lower limit and the true number could be somewhat higher, except in springtime when the measured number of cases can be considered representative. The number of sonde profiles with indications of STE (N1), 


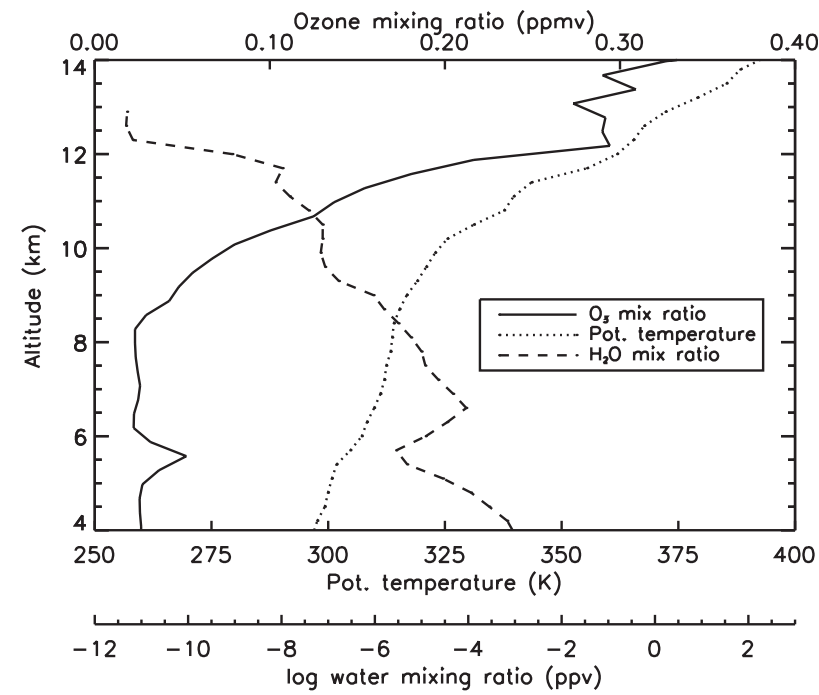

Figure 3. Ozonesonde altitude profiles of $\mathrm{O}_{3}$ mixing ratio, water vapor mixing ratio, and potential temperature, showing air with stratospheric characteristics between 5 and $6 \mathrm{~km}$ on 16 April 1997.

however, is representative during all seasons, since sonde launches do not depend strongly on weather conditions and thus provide a representative sample.

[30] Table 1 shows that usually fewest exchange events over Lauder occur during winter, which was expected from the results of global-scale model studies (see section 2). The difference between other seasons is not significant. The STE frequency varies per year, ranging from $16 \%$ in 1996 to $26 \%$ in 1998. Our study could help to decide when to conduct campaigns aimed at investigation of STE. By performing similar analyses of sonde measurements at other locations, the suitability of the Lauder site for such campaigns could be assessed.

\section{Observations of Low Ozone Amounts Over Lauder in 1997}

[31] In this section a study of the causes of low $\mathrm{O}_{3}$ column densities over Lauder, observed during the 1997 winter and spring, is made. Two previously published articles also address the low $\mathrm{O}_{3}$ amounts observed. Brinksma et al. [1998] showed that record-low $\mathrm{O}_{3}$ amounts over Lauder, measured during August, were caused by a

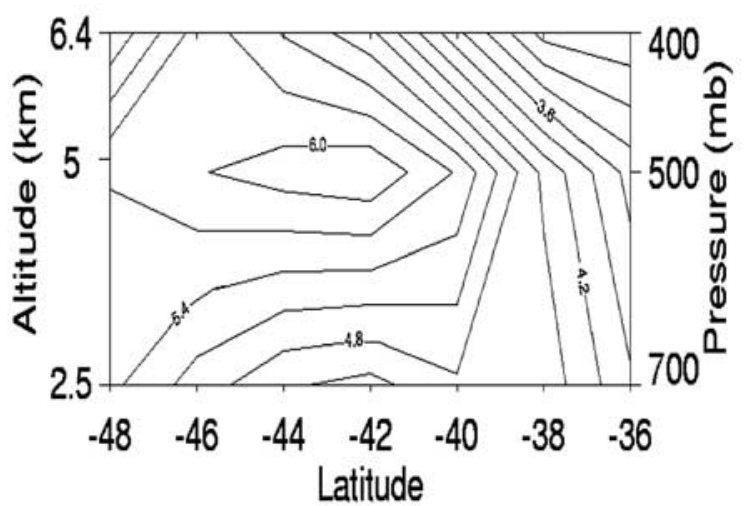

Figure 4. Map of the PV (in units of $-1 \times 10^{-7} \mathrm{Km}^{2}$ $\mathrm{kg}^{-1} \mathrm{~s}^{-1}$, contours separated by $0.3 \times 10^{-7}$ ) at the $170^{\circ} \mathrm{E}$ meridian on 16 April 1997. On the horizontal axis, latitude is depicted (with Lauder at $45^{\circ} \mathrm{S}$ ). On the vertical axes, geopotential altitude (left axis) and pressure (right axis) are depicted. A peak in the absolute value of the PV is evident at an altitude of about $5 \mathrm{~km}$.

juxtaposition of vortex air in the midstratosphere and subtropical air in the lower stratosphere. Similar but less extreme cases observed later in 1997 have been mentioned there, but were not discussed further. Connor et al. [1999] investigated the monthly averaged $\mathrm{O}_{3}$ column density values over Lauder in 1997, showing that between May and November the values were significantly below those of the previous 12 years. They explained this mostly in terms of the long-term trend, the quasi-biennial oscillation, and the El Niño Southern Oscillation. Only the September and October monthly averages were significantly lower than could be explained by their analysis.

[32] Here we investigate these unusually low $\mathrm{O}_{3}$ amounts using $\mathrm{O}_{3}$ profiles as well as column densities. These data are interpreted using analyses of the PV, derived from wind and temperature data provided by the United Kingdom Meteorological Office (UKMO). In the absence of diabatic effects, PV can be regarded as a dynamical tracer [e.g., Hoskins et al., 1985]. On isentropic surfaces in the midlatitude region the $\mathrm{O}_{3}$ mixing ratios are expected to be independent of latitude as well as conserved on timescales of about a week, while air originating from across the polar vortex or the subtropical barrier probably has a different $\mathrm{O}_{3}$

Table 1. Number of Ozonesonde Measurements (N), Number of Measurements in Which STE Evidence Was Detected (N1), Number of Cases of STE Detected (N2), and Percentage (Based on N1/N) ${ }^{\text {a }}$

\begin{tabular}{|c|c|c|c|c|c|c|c|c|c|c|c|c|c|c|c|c|c|c|c|c|c|c|c|c|}
\hline \multirow[b]{2}{*}{ Season } & \multicolumn{4}{|c|}{ Total } & \multicolumn{4}{|c|}{1995} & \multicolumn{4}{|c|}{1996} & \multicolumn{4}{|c|}{1997} & \multicolumn{4}{|c|}{1998} & \multicolumn{4}{|c|}{1999} \\
\hline & $\mathrm{N}$ & N1 & $\mathrm{N} 2$ & $\%$ & $\mathrm{~N}$ & N1 & $\mathrm{N} 2$ & $\%$ & $\mathrm{~N}$ & $\mathrm{~N} 1$ & $\mathrm{~N} 2$ & $\%$ & $\mathrm{~N}$ & N1 & $\mathrm{N} 2$ & $\%$ & $\mathrm{~N}$ & $\mathrm{~N} 1$ & $\mathrm{~N} 2$ & $\%$ & $\mathrm{~N}$ & $\mathrm{~N}$ & $\mathrm{~N} 2$ & $\%$ \\
\hline Summer & 71 & 16 & 11 & 23 & 15 & 5 & 2 & 33 & 15 & 1 & 1 & 7 & 16 & 2 & 2 & 13 & 12 & 5 & 4 & 42 & 13 & 3 & 2 & 23 \\
\hline Autumn & 78 & 17 & 11 & 22 & 25 & 6 & 5 & 24 & 13 & 2 & 1 & 15 & 13 & 5 & 2 & 38 & 13 & 3 & 2 & 23 & 14 & 1 & 1 & 7 \\
\hline Winter & 74 & 11 & 8 & 15 & 19 & 1 & 1 & 5 & 13 & 3 & 1 & 23 & 13 & 1 & 1 & 8 & 14 & 3 & 3 & 21 & 15 & 3 & 2 & 20 \\
\hline Spring & 94 & 22 & 16 & 23 & 25 & 7 & 4 & 28 & 20 & 4 & 3 & 20 & 26 & 6 & 5 & 23 & 14 & 3 & 3 & 21 & 9 & 2 & 1 & 22 \\
\hline Total & 317 & 66 & 46 & 21 & 84 & 19 & 12 & 24 & 61 & 10 & 6 & 16 & 68 & 14 & 10 & 21 & 53 & 14 & 12 & 26 & 51 & 9 & 6 & 18 \\
\hline
\end{tabular}

${ }^{\mathrm{a}}$ These numbers are presented for the complete period, and per season (summer, DJF; autumn, MAM; winter, JJA; spring, SON; where letters denote the first letters of the months included), and were also broken down into individual years. Note that a "year" is defined here to run from December through November. Numbers for 1999 printed in italics exclude November. 


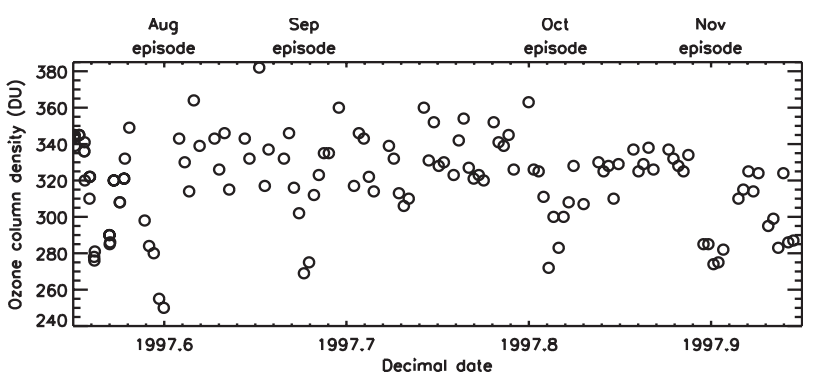

Figure 5. Individual $\mathrm{O}_{3}$ column densities in Dobson units, measured with the Dobson spectrophotometer at Lauder during the 1997 winter and spring, showing four separate low- $\mathrm{O}_{3}$ episodes (labels at the top). The accuracy of the measurements is about $5 \%$.

mixing ratio. In the higher part of the stratosphere (above about $\Theta=580 \mathrm{~K}), \mathrm{O}_{3}$ mixing ratios over the Antarctic are lower than those at midlatitudes throughout the year; high absolute PV values at isentropes above $600 \mathrm{~K}$ thus always indicate $\mathrm{O}_{3}$-poor air.

[33] In the lower part of the stratosphere (below about $\Theta=$ $580 \mathrm{~K}$ ), the situation depends on the time of year; throughout most of the year, high absolute PV values (vortex air) denote high $\mathrm{O}_{3}$ mixing ratios, but after the onset of $\mathrm{O}_{3}$ depletion in late winter (approximately September), mixing ratios decrease strongly, leading to high absolute PV values being associated with low $\mathrm{O}_{3}$ mixing ratios. Very low values of absolute PV in the lower part of the stratosphere indicate $\mathrm{O}_{3}$ poor air, if exchange across the subtropical barrier, which is strongest in winter, has occurred.

\subsection{Dobson Measurements During the 1997 Low-Ozone Episodes}

[34] To study the low- $\mathrm{O}_{3}$ observations, Dobson measurements as well as lidar, ozonesonde, and (during the September episode) SAGE II profile results are used. In Figure 5 all individual $\mathrm{O}_{3}$ column densities measured with the Dobson spectrophotometer at Lauder during the second half of 1997 are presented. Four periods of low $\mathrm{O}_{3}$ column densities stand out (indicated by labels at the top of the figure): early August, early September, late October, and late November. In Table 2 all Dobson results during intervals of time surrounding each of these low- $\mathrm{O}_{3}$ episodes during the winter and spring of 1997 (except August) are listed. The September and October cases are analyzed in subsection 6.2, the November case is analyzed in subsection 6.3, while a detailed analysis of the August case was presented elsewhere [Brinksma et al., 1998].

\subsection{September and October 1997: Higher Vortex Located Over Lauder}

[35] An overview of the $\mathrm{O}_{3}$ column densities measured with the Lauder Dobson spectrophotometer from 1 to 9 September 1997 is presented in Table 2, left column. Particularly low $\mathrm{O}_{3}$ column densities were measured on 5 September at 0024 UT (269 DU) and on 5 September at 2355 UT (275 DU). The 5 September ozonesonde (0441 UT) and lidar (1800 UT) profile measurements were performed in between these moments.

[36] The available measurements of the $\mathrm{O}_{3}$ profiles over Lauder between 31 August and 9 September are presented in Figure 6, both in terms of $\mathrm{O}_{3}$ number density as a function of height, and in terms of $\mathrm{O}_{3}$ mixing ratio as a function of potential temperature $(\Theta)$. They are compared to the averages of 1986-1996 sonde ozone profiles over Lauder.

[37] In the top panel it is evident that the 5 September measurements (solid) deviate significantly from the average $\mathrm{O}_{3}$ profile for this time of year (dashed) at altitudes between about 15 and $30 \mathrm{~km}$. Comparison with the 5 September profile in the bottom panel shows that $\mathrm{O}_{3}$-poor air was present between $\Theta=550-900 \mathrm{~K}$ (about 22-30 km). Between $\Theta=450-500 \mathrm{~K}$ (about $18-20.5 \mathrm{~km}$ ), the mixing ratios are 10 to $25 \%$ below average on 5 September, e.g., at $470 \mathrm{~K}$ the mixing ratio is 0.4 ppmv below the long-term averaged value of $1.8 \mathrm{ppmv}$ for this time of the year.

[38] In the 6 September lidar and ozonesonde profiles (measured simultaneously, at approximately 1115 UT), there is still $\mathrm{O}_{3}$-poor air present between $\Theta=550-850 \mathrm{~K}$ (Figure 6, bottom panel). An $\mathrm{O}_{3}$-rich layer of air is detected between $\Theta=450-550 \mathrm{~K}$ (around $20 \mathrm{~km}$ ). This layer causes an increase in the $\mathrm{O}_{3}$ column density, measured by the Dobson spectrophotometer on 6 September, 2312 UT. By the time of the next measurement on 9 September the profiles were similar to the 1986-1996 mean.

[39] To investigate the origin of the $\mathrm{O}_{3}$-rich and $\mathrm{O}_{3}$-poor air measured in the 1997 winter, high-resolution PV maps were constructed using a reverse trajectory procedure, and initial PV values were calculated from United Kingdom Meteorological Office (UKMO) data. The horizontal resolution of the PV maps is $1^{\circ}$ latitude by $1^{\circ}$ longitude, and the vertical resolution is $2 \mathrm{~km}$. The trajectory calculations were

Table 2. $\mathrm{O}_{3}$ Column Densities Over Lauder During Three Low-O 3 Episodes in $1997^{\mathrm{a}}$

\begin{tabular}{cccccc}
\hline Sept. & $\mathrm{O}_{3}$ Column Density & Oct. & $\mathrm{O}_{3}$ Column Density & Nov./Dec. & $\mathrm{O}_{3}$ Column Density \\
\hline 1 & 346 & 19 & 363 & 19 & 325 \\
2 & 316 & 20 & 326 & 20 & 334 \\
3 & 302 & 21 & 325 & 23 & 285 \\
$5 \mathrm{~A}$ & $\mathbf{2 6 9}$ & $23 \mathrm{~A}$ & 311 & 24 & 285 \\
5 & 275 & 23 & $\mathbf{2 7 2}$ & 25 & $\mathbf{2 7 4}$ \\
6 & 312 & 24 & 300 & 26 & 275 \\
$8 \mathrm{~A}$ & 323 & $25 \mathrm{~B}$ & 283 & 27 & 282 \\
8 & 335 & 26 & 300 & 30 & 310 \\
9 & 335 & 27 & 308 & 1 & 315 \\
\hline
\end{tabular}

${ }^{a}$ Column densities are in Dobson units. Measurements were performed within $\sim 1$ hour from 2300 UT, except dates labeled with "A" (within $\sim 1$ hour from 0100 UT), or "B" (0740 UT). The lowest value in each episode is indicated in boldface. 

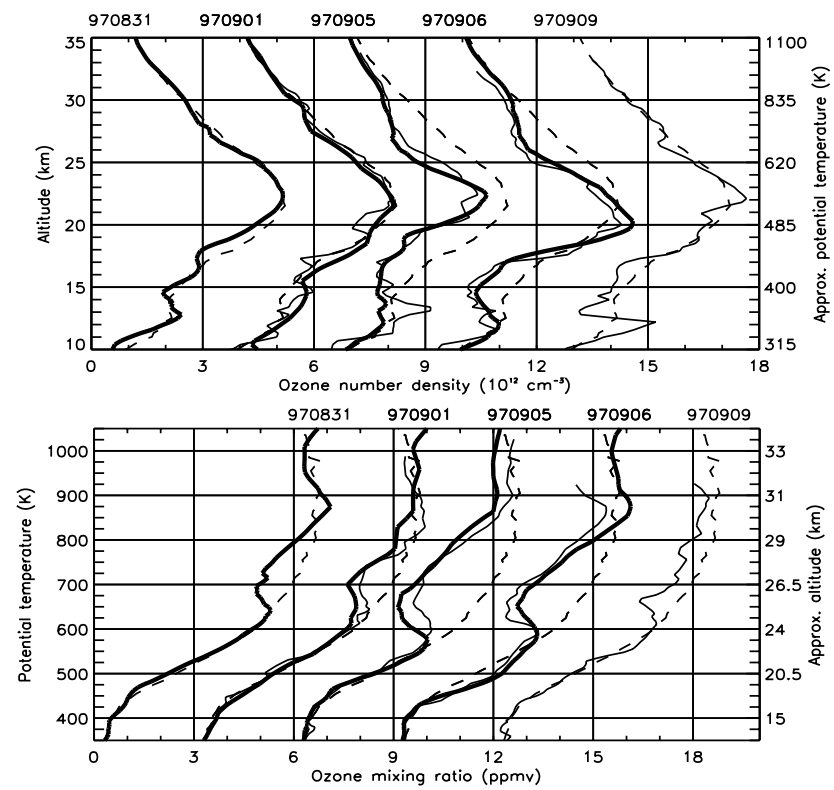

Figure 6. Altitude distributions of $\mathrm{O}_{3}$, measured between 31 August and 9 September 1997. Thick solid lines denote lidar (on 31 August and 5 and 6 September) or SAGE II (on 1 September) results, and thin solid lines denote ozonesonde results. The average of ozonesonde profiles measured between 1986 and 1996 in the period from 28 August through 7 September is superposed on all profiles as a reference (dashed lines). In the top panel, altitude profiles of $\mathrm{O}_{3}$ number density are shown, and in the bottom panel the same data are presented in terms of $\mathrm{O}_{3}$ mixing ratio against potential temperature $(\Theta)$. Measurement results have been offset successively by $3 \times 10^{12} \mathrm{~cm}^{-3}$ (top) or $3 \mathrm{ppmv}$ (bottom), except when two measurements were performed on the same day. Approximate $\Theta$ and altitude scales on the right axes were derived from NCEP data for Lauder on 5 September 1997.

performed using wind fields which were interpolated to isentropic surfaces.

[40] The maps were inspected visually for the presence of relatively high absolute values of PV over Lauder in September 1997, which indicate air of polar origin. The results are summarized in Table 3, where crosses are placed whenever air with high absolute $\mathrm{PV}$ values was located over Lauder (judged by eye from the PV maps at the $\Theta=500$, 600,700 , and $800 \mathrm{~K}$ isentropes). As an illustration, the PV map at $\Theta=800 \mathrm{~K}$ is shown for 5 September, $1200 \mathrm{UT}$

Table 3. Dates and Times at Which, According to PV Maps at Four Isentropes, the Polar Vortex, or Vortex Filaments, Were Located Over Lauder

\begin{tabular}{cccccc}
\hline Sept. & Time, UT & $500 \mathrm{~K}$ & $600 \mathrm{~K}$ & $700 \mathrm{~K}$ & $800 \mathrm{~K}$ \\
\hline 4 & 0000 & & & & \\
4 & 1200 & & & & \\
5 & 0000 & & & $\times$ & $\times$ \\
5 & 1200 & & $\times$ & $\times$ & $\times$ \\
6 & 0000 & $\times$ & $\times$ & $\times$ & \\
6 & 1200 & $\times$ & $\times$ & & \\
7 & 0000 & $\times$ & $\times$ & & \\
7 & 1200 & & & & \\
\hline
\end{tabular}
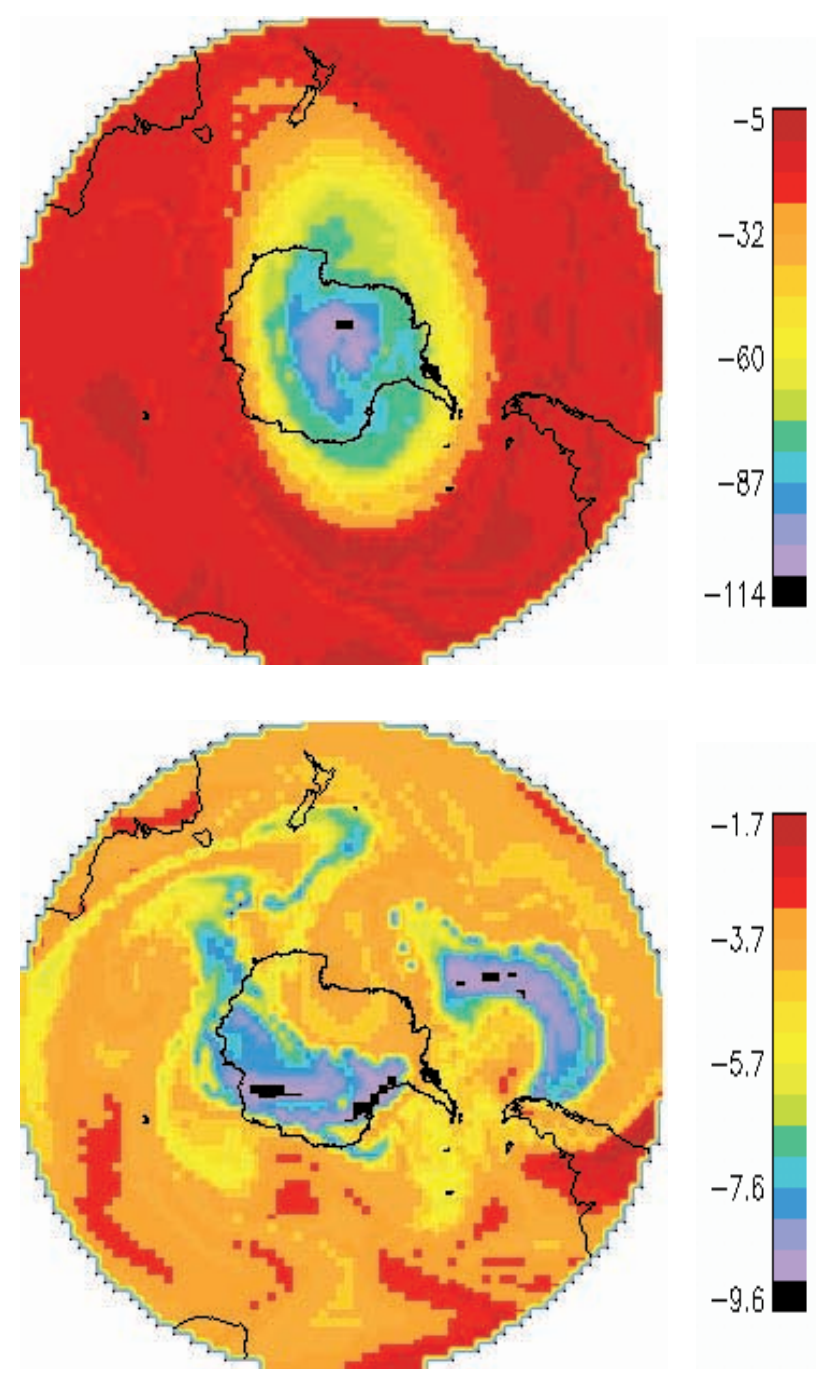

Figure 7. Maps of the PV, generated using a reverse trajectory procedure initialized with UKMO data. The South Pole is in the center of the maps. New Zealand is located near the top of the maps, and Lauder is located in the southern half of its South Island. The PV scale shown in the color bars at the right is in units of $10^{-5} \mathrm{Km}^{2} \mathrm{~kg}^{-1} \mathrm{~s}^{-1}$. (top) Map of the PV at $\Theta=800 \mathrm{~K}$ on 5 September 1997 at 1200 UT, showing a higher vortex filament (containing $\mathrm{O}_{3}$-poor air) over Lauder. (bottom) Map of the PV at $\Theta=550 \mathrm{~K}$ on 27 November 1997 at 0000 UT, showing filaments of the ozone-depleted vortex remnants (high absolute values of PV) over Lauder.

(Figure 7, top panel). Evidently, a filament of the high polar vortex, which is $\mathrm{O}_{3}$-poor throughout the year, was present over Lauder, causing the low $\mathrm{O}_{3}$ mixing ratios observed in Figure 6, bottom panel, at $800 \mathrm{~K}$ on 5 September. On the next day the mixing ratios were more moderate, although still below the average for this time of September, which is associated with the filament of the high vortex moving away from Lauder, as is evident from later PV maps at $\Theta=800 \mathrm{~K}$ (not shown). At the other isentropes listed in Table 3, similar filaments were observed in the PV maps (not shown), and these also passed over Lauder during the 5-7 September period. 

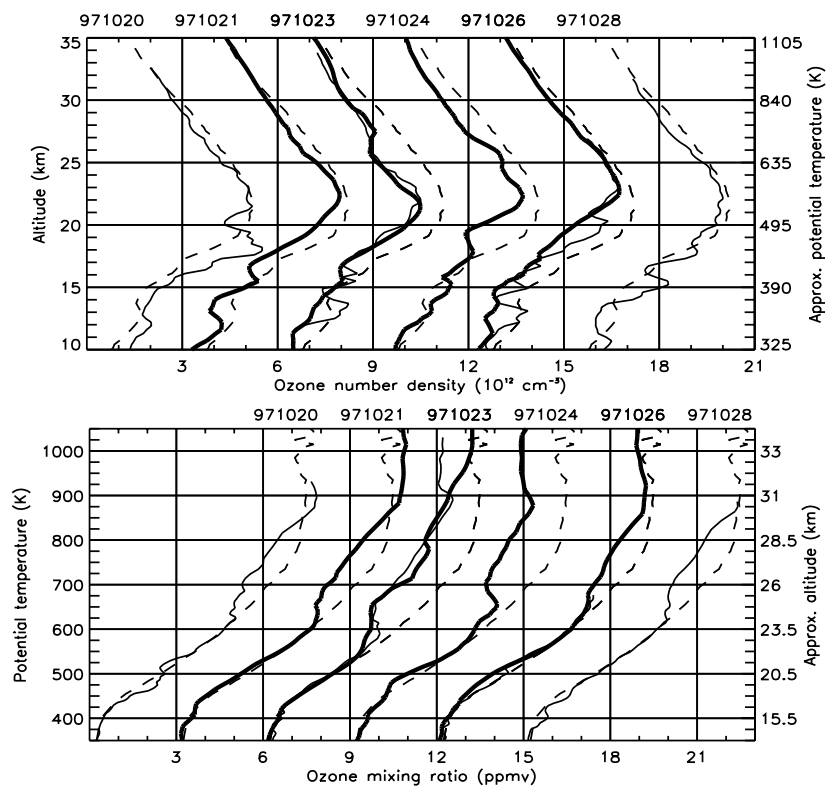

Figure 8. Altitude distributions of $\mathrm{O}_{3}$, measured between 20 and 28 October 1997, with the 1986-1996 average profile between 17 and 27 October superposed as a reference. Plotting conventions as in Figure 6, but now thick solid lines indicate only lidar results. Approximate $\Theta$ and altitude scales on the right axes have been derived from the 23 October 1997 NCEP data.

[41] $\mathrm{O}_{3}$ depletion over the Antarctic happens most effectively during late winter and early spring, which is close in time to the September dates for which $\mathrm{O}_{3}$ profiles were presented. However, it can start during winter in those parts of the vortex that are (temporarily) subject to sunlight [Lee et al., 2000]. For isentropes of $\Theta=600 \mathrm{~K}$ and lower it is not evident whether vortex air in September is $\mathrm{O}_{3}$-rich (as is expected during winter) or $\mathrm{O}_{3}$-poor (as is expected after chemical depletion has taken place). The $\mathrm{O}_{3}$-poor air between $\Theta=450$ and $500 \mathrm{~K}$, detected on 5 September, could indicate transport of chemically depleted Antarctic air. However, the PV maps constructed (not shown) do not provide conclusive evidence of the origin of this layer of air.

[42] In Figure 8 the $\mathrm{O}_{3}$ profiles observed during the low$\mathrm{O}_{3}$ episode of October 1997 are shown. $\mathrm{O}_{3}$ densities deviate less from the average profiles than was the case during September, but otherwise the September and October episodes are similar. On 20 and 21 October, $\mathrm{O}_{3}$-poor air was present between $\Theta=625-850 \mathrm{~K}$. On 20 October, however, an $\mathrm{O}_{3}$-rich layer of air was also present $(450-500 \mathrm{~K})$, mitigating the effect of the $\mathrm{O}_{3}$-poor air on the $\mathrm{O}_{3}$ column densities. The extent of the $\mathrm{O}_{3}$-poor air increased in the next days; on 23 October all air between $\Theta=500-1000 \mathrm{~K}$ was $\mathrm{O}_{3}$-poor, leading to the lowest column density value for this episode (272 DU, see Table 2). In the following days, $\mathrm{O}_{3}$ poor air was gradually replaced by air with mixing ratios more typical for this time of year.

[43] PV maps indicate that low $\mathrm{O}_{3}$ mixing ratios above about $\Theta=600 \mathrm{~K}$ were caused by the higher vortex tilting toward Lauder and moving overhead. This is shown in Table 4, where the presence of air with high absolute PV values over Lauder on the PV maps is indicated by crosses
Table 4. Dates and Times at Which, According to PV Maps at Four Isentropes, the Polar Vortex or Vortex Filaments (crosses), or Low-Latitude Air (L), Were Located Over Lauder

\begin{tabular}{cccccc}
\hline Oct. & Time, UT & $400 \mathrm{~K}$ & $500 \mathrm{~K}$ & $600 \mathrm{~K}$ & $700 \mathrm{~K}$ \\
\hline 22 & 1200 & & $\times$ & & \\
23 & 1200 & & & $\times$ & $\times$ \\
24 & 1200 & $\mathrm{~L}$ & $\mathrm{~L}$ & $\times$ & $\times$ \\
25 & 1200 & $\mathrm{~L}$ & & & \\
26 & 1200 & $\mathrm{~L}$ & & & \\
27 & 1200 & $\mathrm{~L}$ & & & \\
\hline
\end{tabular}

(the PV maps are not shown). $\mathrm{O}_{3}$-poor air was also present at lower altitudes, on 24 and 26 October. This is visible in Figure 8 (bottom panel) between $\Theta=450-525 \mathrm{~K}$ on 24 October, and between $\Theta=450-550 \mathrm{~K}$ on 26 October. This air had a low-latitude origin, as was evident from inspection of PV maps, which showed low values of the absolute PV (maps not shown). Days at which these were present over Lauder are marked with $\mathrm{L}$ in Table 4 . Since $\mathrm{O}_{3}$ mixing ratios are expected to change only slightly on isentropic surfaces between Lauder and the subtropics (as discussed previously), this indicates that mixing has taken place across the subtropical barrier. This will not be investigated further, but in a similar investigation [Brinksma et al., 1998] it was shown that during the August low- $\mathrm{O}_{3}$ episode such mixing did take place.

\subsection{November 1997: $\mathrm{O}_{3}$-Depleted Lower Vortex Filament Located Over Lauder}

[44] Low $\mathrm{O}_{3}$ column densities were measured with the Lauder Dobson spectrophotometer between 23 and 27 November 1997 (see Table 2, right column, and Figure 5).
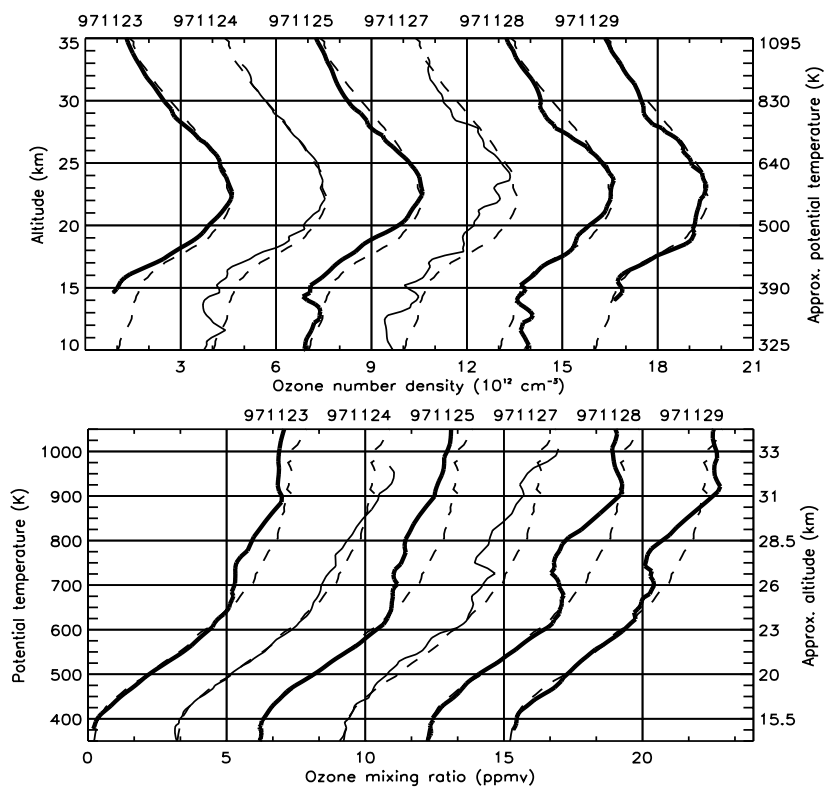

Figure 9. Altitude distributions of $\mathrm{O}_{3}$, measured between 23 and 29 November 1997, with the 1986-1996 average profile between 26 November and 6 December superposed as a reference. Plotting conventions as in Figure 6, but now thick solid lines indicate only lidar results. Approximate $\Theta$ and altitude scales on the right axes have been derived from the 26 November NCEP data. 
$\mathrm{O}_{3}$ profiles, shown in the top panel of Figure 9, show low $\mathrm{O}_{3}$ number densities in various parts of the profiles during this time. Referring to the bottom panel of Figure 9, above $\Theta=$ $650 \mathrm{~K}$ (up to about $900 \mathrm{~K}$ ) the air was $\mathrm{O}_{3}$-poor in all profiles displayed. Between the 450 and $600 \mathrm{~K}$ isentropes, air was only $\mathrm{O}_{3}$-poor on 27 November, indicating that low $\mathrm{O}_{3}$ number densities (in the top panel) at low altitudes on dates other than 27 November must have been caused by warmer, i.e., less dense, air, while on 27 November itself intrinsically $\mathrm{O}_{3}$-poor air was present.

[45] High-resolution PV maps were constructed for 27 November, 0000 UT, which is 1.5 hours before the ozonesonde profile measurement was performed. Inspection of maps on the $\Theta=550 \mathrm{~K}$ isentrope (Figure 7, bottom panel) and on the $500 \mathrm{~K}$ isentrope (not shown) shows that filaments of high absolute PV values (indicating a polar vortex origin) are present over Lauder, coincident with the $\mathrm{O}_{3}$-poor air observed in the ozonesonde profile of 27 November between $\Theta=450$ and $600 \mathrm{~K}$. This shows that $\mathrm{O}_{3}$ depletion which has taken place within the vortex earlier in the spring (when the vortex was still intact) influences $\mathrm{O}_{3}$ amounts observed over Lauder later in the year. The mixing of polar and midlatitude air is known as the dilution effect. The impact of this effect on $\mathrm{O}_{3}$ over New Zealand is discussed elsewhere [Ajtic et al., 2001].

[46] Inspection of maps at higher potential temperatures $(\Theta=600,700$ and $800 \mathrm{~K})$ for 27 November 1997 (not shown) also indicated that the polar vortex had broken up into smaller parts and that one of these parts was in the vicinity of Lauder, causing the low $\mathrm{O}_{3}$ mixing ratios observed. This, however, is not related to Antarctic $\mathrm{O}_{3}$ depletion (which occurs lower down) as the higher vortex is always $\mathrm{O}_{3}$-poor.

\subsection{Conclusions Regarding Low Ozone Observations}

[47] The low- $\mathrm{O}_{3}$ episodes in August [see Brinksma et al., 1998], September, and October (subsection 6.2) of 1997 were in part caused by the $\mathrm{O}_{3}$-poor high vortex $(\Theta$ above about 600 $\mathrm{K})$ moving over Lauder. During August and October, lowlatitude $\mathrm{O}_{3}$-poor air has also contributed. The November low$\mathrm{O}_{3}$ episode was entirely caused by interaction with the former vortex. This shows that even though chemical destruction of $\mathrm{O}_{3}$ took place over the Antarctic, $\mathrm{O}_{3}$ levels over Lauder in late November 1997 were affected by it.

\section{Conclusions and Future Work}

[48] We have presented a set of 5 years of $\mathrm{O}_{3}$ profiles measured with lidar, ozonesondes, and SAGE II, from November 1994 through October 1999. These data were used for an analysis of long-term variability, as well as for several case studies of episodic $\mathrm{O}_{3}$ variations.

[49] The main annual variation over Lauder differed in phase for different altitudes, due to the different processes determining the $\mathrm{O}_{3}$ amounts. Above $30 \mathrm{~km}$ the maximum $\mathrm{O}_{3}$ number densities were measured before midsummer, indicating that processes other than photochemical production must have been significant.

[50] In the future, long-term observations of $\mathrm{O}_{3}$ profiles can be combined with models for studying the processes responsible for changes in $\mathrm{O}_{3}$, and to explain in detail the year-to-year differences that are evident from the measured profiles. Also in the future, trend analysis can be applied to the data, to assess changes in Southern Hemisphere $\mathrm{O}_{3}$ profiles.

[51] Studies of three types of processes relevant for the midlatitude $\mathrm{O}_{3}$ budget were performed. The first type is transport of air from the stratosphere into the troposphere (STE). In the current work, using simultaneously measured profiles of the $\mathrm{O}_{3}$ number density and water vapor mixing ratio, we were able to estimate the STE frequency, which was lowest during June, July, and August, when $15 \%$ of the measured profiles contained evidence of STE. During other months this was about $23 \%$. In the future, analyses should also be applied to the full set of ozonesonde data available (starting in 1986), since changes in the frequency with which exchange events take place could cause trends in $\mathrm{O}_{3}$ observed over Lauder [Bodeker et al., 1998].

[52] To assess the amount of exchange from the stratosphere to the troposphere per year, the number of STE events measured (N2) should be combined with the amount of exchange expected per event. However, this is difficult, because first the three-dimensional size of STE events should be assessed, which is usually done using PV modeling [e.g., WMO, 1985; Price and Vaughan, 1993], which could be combined with satellite $\mathrm{O}_{3}$ maps. Second, the typical amount of irreversible transport in a tropopause fold should be estimated, because only part of the $\mathrm{O}_{3}$ is mixed in with the troposphere, whereas another part returns to the stratosphere. This requires detailed modeling of the dynamics in the frontal system associated with the tropopause fold, which is very hard, and consequently, estimates for typical exchange amounts in a tropopause fold vary strongly (for more details, see $W M O$ [1985]).

[53] The second process studied involved the positioning of the higher polar vortex over Lauder, contributing to several low- $\mathrm{O}_{3}$ episodes during winter and spring of 1997. Using back trajectory calculations, the September and October low- $\mathrm{O}_{3}$ episodes were shown to be related to the higher polar vortex being located over Lauder. In October and possibly also in September, exchange between low latitudes and midlatitudes also contributed. The August 1997 case, in which record-low $\mathrm{O}_{3}$ column densities were observed, was presented elsewhere [Brinksma et al., 1998].

[54] The third process studied pertains to exchange between the lower vortex and midlatitudes, after chemical $\mathrm{O}_{3}$ depletion had rendered the lower vortex $\mathrm{O}_{3}$-poor, and the vortex itself had broken up. High-resolution PV maps showed that air from the broken up vortex was mixed into midlatitude regions, leading to low $\mathrm{O}_{3}$ column densities observed over Lauder during late November 1997.

[55] Acknowledgments. We are grateful to Frank Ormel, Yasjka Meijer, Folkert Boersma, Andrew Cunningham, and Michael Kotkamp for performing lidar measurements (jointly with E.B.), to the NIWA staff for performing ozonesonde measurements, and to J. Zawodny for making the SAGE II data available. B. J. Connor and D. P. Donovan are acknowledged for providing useful comments on an earlier version of this article.

\section{References}

Ajtic, J., B. Connor, C. Randall, G. Bodeker, B. Lawrence, and R. Bevilacqua, The impact of vortex breakdown on ozone over New Zealand in 1998 , Eos Trans. AGU, 82(20), Spring Meet. Suppl., Abstract A41B-03, 2001. Andrews, D. G., J. R. Holton, and C. B. Leovy, Middle Atmosphere Dynamics, Academic, San Diego, Calif., 1987. 
Bodeker, G. E., I. S. Boyd, and W. A. Matthews, Trends and variability in vertical ozone and temperature profiles measured by ozonesondes at Lauder, New Zealand: 1986-1996, J. Geophys. Res., 103, 28,66128,681, 1998.

Brinksma, E. J., et al., Analysis of record-low ozone values during the 1997 winter over Lauder, New Zealand, Geophys. Res. Lett., 25, 2785-2788, 1998.

Brinksma, E. J., et al., Validation of 3 years of ozone measurements over Network for the Detection of Stratospheric Change station Lauder, New Zealand, J. Geophys. Res., 105, 17,291-17,306, 2000.

Connor, B. J., G. E. Bodeker, R. L. McKenzie, and I. S. Boyd, The total ozone anomaly at Lauder, NZ, in 1997, Geophys. Res. Lett., 26, 189192, 1999.

Fahey, D. W., et al., In situ observations of $\mathrm{NO}_{y}, \mathrm{O}_{3}$, and the $\mathrm{NO}_{y} / \mathrm{O}_{3}$ ratio in the lower stratosphere, Geophys. Res. Lett., 23, 1653-1656, 1996.

Fleagle, R. G., and J. A. Businger, An Introduction to Atmospheric Physics, 2nd ed., pp. 72 and 90, Academic, San Diego, Calif., 1980.

Holton, J. R., P. H. Haynes, M. E. McIntyre, A. R. Douglass, R. B. Rood, and L. Pfister, Stratosphere-troposphere exchange, Rev. Geophys., 33, 403-439, 1995.

Hoskins, B. J., M. E. McIntyre, and A. W. Robertson, On the use and significance of isentropic potential vorticity maps, Q.J. R. Meteorol. Soc., 111, 877-946, 1985.

Lee, A. M., H. K. Roscoe, and S. J. Oltmans, Model and measurements show Antarctic ozone loss follows edge of polar night, Geophys. Res. Lett., 27, 3845-3848, 2000.

McKenzie, R., B. Connor, and G. Bodeker, Increased summertime UV radiation in New Zealand in response to ozone loss, Science, 285, 1709-1711, 1999.

McPherson, R. D., K. H. Bergman, R. E. Kistler, G. E. Rasch, and D. S. Gordon, The NMC operational global data assimilation system, Mon. Weather Rev., 107, 1445-1461, 1979.

Perliski, L. M., S. Solomon, and J. London, On the interpretation of seasonal variations of stratospheric ozone, Planet. Space Sci., 37, 15271538, 1989.

Price, J. D., and G. Vaughan, On the potential for stratosphere-troposphere exchange in cut-off low systems, Q. J. R. Meteorol. Soc., 119, 343-365, 1993.

Schoeberl, M. R., and D. L. Hartmann, The dynamics of the stratospheric polar vortex and its relation to springtime ozone depletions, Science, 251, 46-52, 1991.

Shapiro, M. A., Turbulent mixing within tropopause folds as a mechanism for the exchange of chemical constituents between the stratosphere and the troposphere, J. Atmos. Sci., 37, 994-1004, 1980.

Solomon, S., Stratospheric ozone depletion: A review of concepts and history, Rev. Geophys., 37, 275-316, 1999.

Trepte, C. R., and M. H. Hitchman, Tropical stratospheric circulation deduced from satellite aerosol data, Nature, 355, 626-628, 1992.

Waugh, D. W., Subtropical stratospheric mixing linked to disturbances in the polar vortices, Nature, 365, 533-535, 1993.

Weatherhead, E. C., et al., Detecting the recovery of total column ozone, $J$. Geophys. Res., 105, 22,201-22,210, 2000.

World Meteorological Organization (WMO), Atmospheric ozone 1985Assessment of our understanding of the processes controlling its present distribution and change, vol. 1, Rep. 16, Global Ozone Res. and Monit. Proj., Geneva, 1985.

J. Ajtic, Department of Physics and Astronomy, University of Canterbury, Private Bag 4800, 8020 Christchurch, New Zealand. (j.ajtic@phys. canterbury.ac.nz)

J. B. Bergwerff and D. P. J. Swart, Air Research Laboratory, National Institute of Public Health and the Environment, P.O. Box 1, 3720 BA Bilthoven, Netherlands. (hans.bergwerff@rivm.nl; daan.swart@rivm.nl)

G. E. Bodeker, National Institute of Water and Atmospheric Research (NIWA), Private Bag 50061, Omakau, 9182 Central Otago, New Zealand. (g.bodeker@niwa.cri.nz)

I. S. Boyd, Department of Astronomy, University of Massachusetts, Amherst, MA 01003, USA. (i.boyd@niwa.com)

E. J. Brinksma and J. F. de Haan, Climate Research and Seismology Department, Atmospheric Composition Research Division, KNMI, P.O. Box 201, 3730 AE De Bilt, Netherlands. (brinksma@knmi.nl; johan.de. haan@knmi.nl)

W. Hogervorst and J. W. Hovenier, Faculty of Sciences, Division of Physics and Astronomy, Vrije Universiteit, De Boelelaan 1081, 1081 HV Amsterdam, Netherlands. (wh@nat.vu.nl; hovenier@nat.vu.nl) 